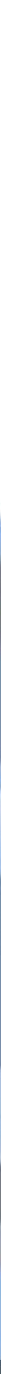

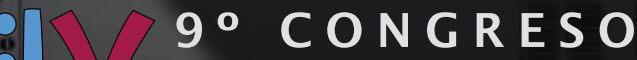
2. CENTROAMERICANO DE H IS TO R I A
Universidad de Costa Rica

ISSN 1409-469X

Fecha de recepción: 15 de mayo 2008 Fecha de aceptación: 30 de mayo 2008

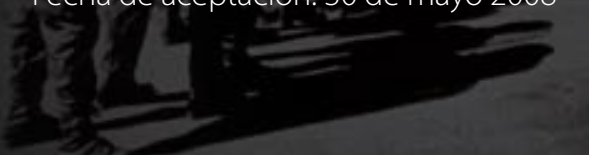

La educación formal del clero secular en la Diócesis de Nicaragua y Costa Rica

Miembros del Consejo Editorial:

Dr. Ronny Viales, Dr. Juan José Marín

Editores Técnicos:

Allan Fonseca, Andrés Cruz, Gabriela Soto

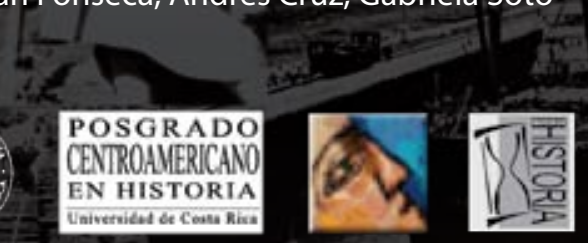


Indexaciones: Repositorio de Revistas UCR, DIALNET, Latindex, REDALYC Directorio y recolector de recursos digitales del Ministerio de Cultura de España, Directory of Open Access Journals. Diálogos Revista Electrónica de Historia ISSN 1409-469X. Número especial 2008. Dirección web: http://historia.fcs.ucr.ac.cr/dialogos.htm

\section{La educación formal del clero secular en la Diócesis de Nicaragua y Costa Rica}

Dra. Carmela Velázquez Bonilla

Escuela de Historia

CIHAC

Universidad de Costa Rica

Teléfono (506) 22217234

(506) 83832770

email:carmelav@racsa.co.cr 


\section{Introducción}

Los trabajos sobre la Diócesis de Nicaragua y Costa Rica, han analizado la organización interna y externa, el cabildo catedralicio, las relaciones políticas y la religiosidad pero han dejado de lado la educación del clero secular, tanto de los dirigentes como los sacerdotes que estuvieron al frente de las parroquias de las ciudades y los pueblos. Al respecto se han creado aseveraciones un poco a la ligera sobre su escasa preparación académica, por lo que decidimos realizar esta investigación para conocer dentro de los posible cuál fue la realidad de la preparación del clero secular de la diócesis. Nos enfocaremos sobre todo a la educación formal, la que consideraremos como la obtenida en León en el Seminario San Ramón Nonato, que se complementaría en muchos casos con los grados que otorgaba la Universidad de San Carlos y el Colegio San Francisco de Borja de los jesuitas, ambos en Guatemala.

La educación del clero secular en todas las diócesis debió de estar bajo el cuidado de los obispos, quienes debieron de velar sobre todo por la educación formal como lo pedía el Concilio de Trento. La preparación se iniciaba en muchos casos desde muy temprana edad y para costear esos estudios era necesario que tuviera una renta que se lo permitiera como lo había expresado también el Concilio de Trento. ${ }^{1}$

Una de las fuentes principales de estas rentas las constituyeron las capellanías, por lo que muchos testadores instituyeron capellanías en sus testamentos para tratar de que alguno de sus descendientes se hiciera sacerdote, a cambio, el beneficiario debía retribuir la ayuda con la celebración de misas por la salvación de su alma. Los bienes sobre los que se instituía la renta podían ser ganado, bienes inmuebles y riquezas en general. Esta renta era de un 5\% sobre los bienes. En otros casos, se estipulaba la cantidad de dinero que debía otorgase al beneficiario en total o se le asignaba una cantidad por la celebración de las misas, ya fueran por su alma o por alguno de su encargo, como sería el caso de sus padres. ${ }^{2}$

Varios de los sacerdotes que gozaron de una capellanía para su formación, también las instituyeron luego, o se convirtieron en patronos para que se siguieran administrando los bienes de estas y así se pudieran seguir celebrando las misas por quienes las establecieron.

1 William B. Taylor, Ministros de lo Sagrado. (México, El Colegio de Michoacán, El Colegio de México. Secretaría de Gobernación. 1999), 184.

2 Carmela Velázquez, Las actitudes ante la muerte en el Cartago del siglo XVII. (Tesis de maestría del posgrado centroamericano en Historia de la Universidad de Costa Rica, 1996), 95. 


\section{La educación formal}

Como ya se señaló, los obispos eran los principales responsables de la educación del clero secular, por recomendación del concilio de Trento y en el mundo hispánico, se reforzó con las cédulas reales de los monarcas. En los decretos tridentinos se advertía a los párrocos y prelados que "una de sus primeras obligaciones era instruir a los fieles, pero para eso tendrían que haber sido ellos mismos instruidos.”3 La iglesia novohispana discutió el tema de la formación de los clérigos en todos los sínodos y concilios provinciales. En el primero de 1555, se fijaron los conocimientos mínimos para conceder los grados de las órdenes sagradas. En 1592, Felipe II encomendó a todos los obispos que fundaran seminarios, a la vez que pedía a los virreyes y gobernadores que alentaran las fundaciones y les dieran el auxilio necesario. Para ingresar a los seminarios y para obtener otorgamiento de beneficios al finalizar los estudios, era lo más recomendable que se eligiese a los hijos descendientes de los conquistadores y pobladores. Estas mismas disposiciones fueron ratificadas por Felipe III y Felipe IV. Pero a pesar de todas las recomendaciones para que se fundaran seminarios, estos tardaron un tiempo en surgir ${ }^{4}$

El primer seminario que se fundó en México, fue en Puebla, en 1644, por iniciativa del obispo Juan de Palafox Mendoza, ya que él consideraba que el clero secular era la columna vertebral de la Iglesia. Años más tarde en 1670, en Oaxaca se fundó otro seminario.

En Panamá el seminario tridentino fue fundado en 1613, en la ciudad de Panamá. ${ }^{5}$ En el caso de Chile la creación del seminario fue muy temprana, se dio luego del Concilio de Lima de 1583, en que se enfatizó que se debían de crear los seminarios tridentinos, pero este seminario de Concepción, desapareció luego de la gran rebelión indígena de 1600. Por lo que en el siglo XVII su existencia no fue continua y no es sino hasta 1718 en que el obispo Juan de Necolalde fundó un seminario en 1718, es decir durante ciento veinte años la diócesis no tuvo seminario. Lo que repercutió negativamente en la preparación del clero de Chile. ${ }^{6}$

En el Caribe, en Cuba nos encontramos que el seminario tridentino fue erigido por el Obispo Cabezas Altamirano en 1605. ${ }^{7}$ En Guatemala el seminario conciliar inició sus labores el 3 Pilar Gonzalo Aizpuru, Historia de la Educación en la época colonial. La educación de los criollos y la vida urbana.(México, El Colegio de México, 1999), 307

$4 \quad$ Ibid.,308.

$5 \quad$ Alfredo Castillero. Historia General de Panamá. Vol. I, Tomo II. (Panamá, Comité Nacional del Centenario, D Vinni Impresores, 2004), 310.

$6 \quad$ Lucrecia Enríquez Agrazar. De colonial a nacional: La carrera eclesiástica del clero secular chileno entre 1650 y 1810.(México, Instituto Panamericano de Geografía e Historia, 2006), 153.

$7 \quad$ www.vitral.org/vitral/vitral28/domin.htm. Consulta 10 de mayo del 2008. 
12 de julio de 1598. Se estableció en lo que hoy llamaríamos Antigua Guatemala y continuó en sus labores hasta $1970 .^{8}$

Como podemos observar con estos cuatro ejemplos, de diferentes espacios de América, la creación de seminarios conciliares fue una política en las diferentes diócesis americanas, para cumplir con las órdenes del Concilio de Trento y de la Corona con el fin de preparar a los sacerdotes para que estos pudieran transmitir a sus fieles la doctrina.

En el caso de la Diócesis de Nicaragua y Costa Rica, desde muy temprano, en 1591, los obispos en sus documentos manifestaron la queja de la desventura de que "esta provincia por su pobreza, que no haber en ella una Cátedra de Gramática para que los hijos de los españoles que en ella viven la aprendan y se ordenasen, porque si esta Cátedra hubiese, también habría clérigos de la propia tierra que supiesen las lenguas." ${ }^{9}$ En el mismo documento fray Domingo de Ulloa expresó que elaboró una doctrina y un confesionario que debía ser traducido a las diferentes lenguas para que los indígenas "por el Doctrinario se doctrinen y se enseñen los naturales y por el confesionario se confiesen." 10

La preocupación de conocer la lengua de los indígenas para poderlos catequizar, la manifestó fray Jerónimo de Escobar en la carta de aceptación de su nombramiento como obispo de Nicaragua y Costa Rica en 1592, “... y ansí tendré necesidad de aprender de nuevo la lengua de esta gente, porque pues Dios me ha hecho Pastor es bien que si la oveja se me quejare la entienda para curarla." ${ }^{11}$ En 1672, el obispo Alonso Bravo y Lagunas insistió también en la necesidad de las cátedras de Gramática y de Lengua para cumplir con el deseo de la Corona de que los sacerdotes hablaran la lengua vernácula. Como se puede observar, existió por parte de los obispos la preocupación de que los sacerdotes se prepararan para conocer las lenguas de los indígenas para comunicarse con ellos y trasmitirles las enseñanzas cristianas.

La necesidad de un seminario conforme lo ordenaba el Concilio de Trento se evidenció en la Diócesis de Nicaragua y Costa Rica, en las bulas del nombramiento del obispo Juan de la Torre en $1661 .{ }^{12}$ Sin embargo, no fue sino hasta octubre de 1677 que la Corte de Madrid, por medio de

8 Estrada Monroy, Agustín. Datos para la Historia de la Iglesia de Guatemala. Tomo I. (Guatemala, Tipografía Nacional,1972),194.

9 Archivo General de Indias, en adelante AGI. Guatemala, 162. Granada, 15 de febrero de 1591.

10 Ibíd.

11 AGI, Guatemala, 162. Madrid, 10 de agosto de 1592.

12 AGI, Guatemala, 162, Roma, 20 de diciembre de 1661. 
Cédula Real fechada 13 de octubre, dio instrucciones al obispo de Nicaragua para que fundara dos cátedras en la ciudad de León, una de Gramática para la educación de los jóvenes y otra de la lengua materna de los indios para que los clérigos pudieran ejercer mejor su labor pastoral; sus dotaciones vinieron consignadas sobre los tributos de encomiendas sin beneficiarios. ${ }^{13} \mathrm{El}$ obispo fray Andrés de las Navas y Quevedo dispuso tomar las medidas necesarias para crearlas y, por lo tanto, fijó los edictos necesarios para que se despacharan las nóminas al gobierno superior y en nombre de Vuestra Majestad, "se dio título Real en la cátedra de la lengua, al licenciado Cristóbal Gutiérrez, presbítero, y en la de gramática al licenciado Antonio Díaz de la Expiella, que hoy quedan en actual ejercicio y educación de la juventud.”14

En 1679, en el afán de que se cumpliera con lo establecido en Trento y en los requerimientos de la Corona y de los Concilios Americanos, la Audiencia de Guatemala urgió a los obispos de Comayagua y León para que hicieran realidad el decreto tridentino sobre la fundación de un seminario en cada diócesis. Ante esta solicitud, fray Andrés de las Navas, como lo había hecho con las cátedras de Gramática y de Lengua, actuó dando los pasos necesarios para fundar el seminario. Con ese fin, realizó la siguiente concesión: “...mis casas propias donación irrevocable para dicho ministerio siendo así que dichas casas las había comprado del Capitán Bartolomé Roque vecino de esta ciudad con cargo y obligación de cincuenta misas y un aniversario en cada año."15

De esa manera, El Colegio Seminario de San Ramón Nonato se estableció en León en 1680 y tuvo sede permanente en las inmediaciones de la Catedral de León. El nuevo seminario estuvo bajo la advocación de San Ramón Nonato, santo muy venerado por los mercedarios, por lo que posiblemente lo escogió el también el obispo mercedario de las Navas y Quevedo.

Otro de los aportes significativos del mismo obispo fue donar seiscientos pesos de su propio peculio para comprar muebles o útiles escolares y además, entregó parte de los diezmos que le correspondían, ya que la contribución de los curatos ordenada por el Concilio de Trento no era suficiente. ${ }^{16}$

13 Edgar Zúñiga. Historia Eclesiástica de Nicaragua. 2ed. (Managua, Hispamer, 1996), 163.

14 Carta del Ilustrísimo D. Fray Andrés de Navas a su Majestad sobre fundación de dos cátedras en León de Nicaragua. En: Estrada, 362.

$15 \quad$ AGI, Guatemala 162, 21 de octubre 1679, fo. 427.

16 Zúñiga,164. 


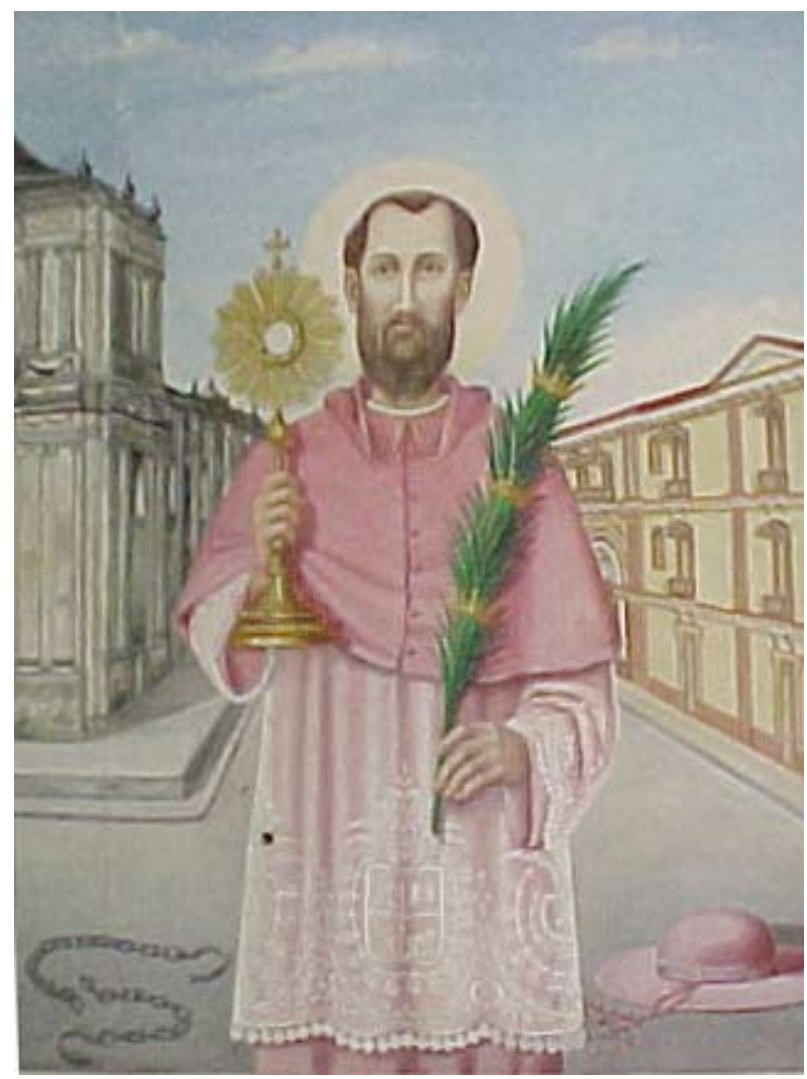

Lámina 1. San Ramón Nonato, entre el seminario de su nombre y la catedral de León, lo que simboliza la preocupación de la Iglesia por

la educación de los sacerdotes. ${ }^{17}$

Una vez establecido el seminario los obispos continuaron protegiéndolo y buscando que se pudiera sostener a través del tiempo, encontramos que: Dionisio de Villavicencio (17311735), cambió la cátedra del seminario de lengua indígena por la de Artes y Teología Moral y patrocinó personalmente una clase de solfeo para que los eclesiásticos cantaran mejor los oficios litúrgicos. ${ }^{18}$ En el caso del obispo Pedro Agustín Morel de Santa Cruz, exigió el cobro de los impuestos a favor del seminario y pagó el sueldo del preceptor de gramática para librar de este trabajo al rector. Además abrió el curso de filosofía en su palacio Episcopal con 22 estudiantes

17 Pintura de la pinacoteca del Seminario San Ramón nonato de la ciudad de León en Nicaragua.

18 Zúñiga,196. 
manteniéndolos de su propio peculio. ${ }^{19}$ También se preocupó por el edificio en el que estaba instalado el seminario, el que se encontraba en muy malas condiciones y amenazaba caerse. Ante esta situación decidió venderlo en 1600 pesos y compró un terreno en el costado Sur de la catedral de León, lugar en el que todavía se encuentra hoy. Encargó los planos al arquitecto Diego de Porres, que había venido de Guatemala a trabajar en la catedral. De Porres presentó los planos ya aprobados y comenzó la edificación el 12 de octubre de 1752 bajo la dirección del maestre de campo don Francisco Benítez de Salafranca. El Nuevo edificio fue entregado el 8 de junio de 1753 y en él tomó posesión el rector don Bernardo Valdivia.

En el caso del obispo Carlos Vílchez y Cabrera, (1764-1774), este logró que se emitiera el 16 de diciembre de 1771, la Cédula Real en que se creaban las cátedras de Filosofía, Teología, Cánones y Sagradas Escrituras para las que brindó su aporte. ${ }^{20}$ Luego vino el obispo Esteban Lorenzo Tristán (1777-1783) que fomentó las artes liberales y mecánicas de la industria de los hilados y tejidos de algodón. Además fundó varios centros de enseñanza adscritos al Seminario San Ramón y uno de los profesores de estos centros fue el padre Rafael Agustín Ayestes. ${ }^{21}$ El siguiente obispo que ejerció de 1786 a 1793, Juan Félix Villegas, en 1787 le confirió la rectoría al padre Ayestes, quien fue durante más de 30 años maestro de ceremonias de la catedral de León, lo que lo hizo una autoridad en estudios litúrgicos. Otro de los trabajos que tomó Ayestes fue la educación de los niños pobres de los que algunos llegaron al sacerdocio como el caso de Pedro Solís que llegó luego a ser secretario del obispo de la Huerta Caso.

El obispo de la Huerta Caso manifestó una gran dedicación por el seminario, lo que lo llevó a aumentar de su propio peculio las cátedras de Sagrada Escritura, Liturgia, Historia Eclesiástica, Derecho, Medicina y Filosofía. Además confirmó en 1799 a don Miguel Larrainaga en las cátedras de Filosofía y retórica. ${ }^{22}$

Como se ha podido observar la preocupación por la educación en general, por el Seminario San Ramón en el mejoramiento de sus cátedras y de su edificio se ha podido evidenciar en lo anteriormente establecido. Lo que nos debemos de cuestionar es si bien había un mandato conciliar para que los obispos estuvieran al cargo de la educación y de los seminarios, se nos hace muy importante conocer la preparación formal de estos obispos para poder comprender mejor sus actuaciones.

\begin{tabular}{ll}
\hline 19 & Ibid., 205. \\
20 & Zúñiga, 217. \\
21 & Ibid., 221. \\
22 & Ibid., 234
\end{tabular}




\section{La preparación de los obispos}

Nos encontramos que ya en 1604 el primer Obispo secular que llegó a León, don Pedro Villarreal, tenía el título de doctor, pero no se conoce en dónde lo obtuvo. Luego llegó a la diócesis en 1635 el benedictino Benito Baltodano, con su título de doctor obtenido en la Universidad de Salamanca. En 1646 se incorporó como obispo el franciscano Alonso Briceño, a él lo consideran el teólogo más importante que rigió la diócesis, estudió 15 años de carrera universitaria, ganó la cátedra de filosofía y por tres años enseñó artes, luego por 12 años enseñó teología. Escribió 3 volúmenes sobre Escoto Prima pars celebriorum controversarium in Primun Sententiarum Joannis Scoto etc de la cual se publicaron 2 volúmens en Madrid 1638-1644. Algunos lo consideran el mayor Escotista americano. ${ }^{23}$

Ya establecido el seminario encontramos en 1722, que el primer Obispo nacido en Nicaragua, José Xirón, dominico, fue uno de los primeros alumnos de la Universidad de San Carlos de Guatemala. Publicó en 1720 en Guatemala Novenas y disposiciones para celebrar debidamente la encarnación del Verbo divino recopilada de varios autores. ${ }^{24}$

También llegaron a presidir la diócesis dos doctores, Domingo de Zataraín en 1738 e Isidro Marín en 1746. Posteriormente llegó el dominicano licenciado Pedro Agustín Morel de Santa Cruz, en 1751. Luego, cuando fue trasladado a Cuba para convertirse en el obispo de esa isla, se preparó ahí y se convirtió en doctor. ${ }^{25}$ En cuanto al obispo Vílchez y Cabrera, (1764 a 1774), se le conoce como doctor pero desconocemos cuál fue el centro de estudios en donde obtuvo ese grado. ${ }^{26}$ También con un doctorado se incorporó a su puesto de obispo en 1775, Esteban Lorenzo de Tristán. ${ }^{27}$

El doctor Juan Félix Villegas graduado en ambos derechos estuvo al frente de la diócesis fue profesor en la Universidad de Valladolid. Había sido provisor y Vicario general de Santa Fe de Bogotá y rector del Colegio Seminario Real Mayor de San Bartolomé de Santa Fe de Bogotá. Un caso muy interesante es el del obispo José Antonio de la Huerta Caso, con un nombramiento desde 1798 a 1803 en que falleció, era nicaragüense y fue alumno del seminario San Ramón

\footnotetext{
23 Zuñiga, 133.

$24 \quad$ Ibid., 188.

25 AGI.,Guatemala, 362. Relación de los Méritos grados y servicios del Licenciado D. Pedro Agustín Morel de Santa Cruz, deán de la Iglesia Catedral de la Ciudad de Santiago de Cuba., 1735.

26 Bernardo Augusto Thiel, Datos Cronológicos para la Historia Eclesiástica de la Iglesia de Costa Rica. Editado por José Albeto Quirós. (San José, UNICLERO), SA, 2002), 419

27 Thiel, 376.
} 
Nonato, en donde obtuvo el título de bachiller. También el obispo Nicolás García Jerez fue Doctor y Maestro en Sagrada Teología, este fue uno de los últimos obispos de la diócesis ya que ingresó en 1810 y estuvo hasta 1824.

Luego de conocer la preparación de los obispos que llegaron a la Diócesis de Nicaragua y Costa Rica, considerada una Diócesis pobre, alejada y con poca población, encontramos que en los 319 años en que existió la diócesis de Nicaragua y Costa Rica, es decir de 1531 a 1850. Los obispos consagrados de la diócesis fueron 31 además hemos encontrado información de que 12 tuvieron educación superior, esto nos da que un 38\% de los prelados llegados a León venían con una buena preparación y es muy posible que por eso vivieron la preocupación tan grande por educar a los futuros sacerdotes de su diócesis.

El Seminario San Ramón Nonato se convirtió en Universidad en 1812, con las mismas facultades de las otras universidades americanas.

\section{El clero secular}

Luego de analizar el estado de preparación formal de los obispos de la diócesis, consideramos muy importante conocer si los miembros del clero secular, los que estaban en las parroquias y por consiguiente con un mayor contacto con los fieles, tuvieron alguna preparación.

Cada diócesis contaba con cierto número de sacerdotes, quienes estaban al frente de las parroquias; ellos dependían directamente del obispo y sus actuaciones estaban regidas por el Derecho Canónico. Cuando estaban en una parroquia, se les consideraba como curas beneficiados y eran nombrados, y pagados por el Real Patronato.

Después de los obispos, los sacerdotes fueron los encargados de dirigir el culto en la diócesis; celebraban las misas, participaban en las procesiones, festejaban a los santos patronos de los pueblos y ciudades, y a los de las cofradías; bautizaban, daban la primera comunión, casaban y celebraban el funeral de sus feligreses. Además, entre sus obligaciones estaba preocuparse por acudir a los moribundos, tratar de que no murieran sin testar y efectuar sus funerales, sus misas de novenario y las que el difunto encargara en su testamento para después de muerto. También debían cuidar del mantenimiento de los templos; de los gastos para realizar el culto; llevar los libros de cuentas de las iglesias, conocidos como libros de fábrica. Todas esas actividades $\underline{\text { permitieron que los sacerdotes tuvieran mucha relación con su grey. }{ }^{28}}$

28 Carmela Velásquez,El Sentimiento religioso y sus prácticas en la Diócesis de Nicaragua y Costa Rica. Siglos XVII y XVIII. Tesis del sistema de Pos grado de la Universidad de Costa Rica, 2004,128 
La preparación del clero de Costa Rica, no se llevó a cabo en Cartago su capital, por que no habían centros que lo permitieran, como lo señala Iván Molina:

"Pese a las importantes limitaciones educativas de Costa Rica en el período colonial, algunos jóvenes lograron realizar estudios fuera de la provincia, esencialmente para formarse como eclesiásticos, ya fuera en la Universidad de San Carlos de Guatemala o en el Colegio de San Ramón de León (Nicaragua). En buena medida, la base financiera de tales experiencias se basó en la fundación de capellanías. ${ }^{29}$

Para conocer la educación del clero en la Diócesis de Nicaragua y Costa Rica, analizaremos algunos casos para tener una idea de su preparación. Empezaremos con el padre Baltasar de Grado, “el primer costarricense que alcanzó la dignidad del sacerdocio.”30 Fue llevado por monseñor Villarreal a Nicaragua luego de su visita pastoral a Costa Rica en 1608, para que recibiera instrucción eclesiástica y luego lo ordenó sacerdote. Con este primer sacerdote costarricense, podemos observar lo que fue la constante durante el periodo colonial, llevar a los sacerdotes a estudiar a Nicaragua. Los documentos lo mencionan como licenciado, pero no se señala el lugar en que obtuvo este grado académico. Y en el momento en que partió para Nicaragua todavía no estaba establecido el Seminario San Ramón que nació en 1680.

Más o menos por el tiempo en que se ordenó Baltasar de Grado, recibió también la ordenación el primer sacerdote nacido en Nicaragua, en la ciudad de Granada, el padre Luís Díaz Bautista que en 1614, fue designado como canónigo de la catedral de León. ${ }^{31}$ Años después partió para Nicaragua a estudiar don Domingo de Echavarría Navarro, que fue sobrino nieto de Baltasar de Grado, no sabemos del año de su partida para Nicaragua solo conocemos que en 1657 convino en permutar su puesto de cura en León con don Diego de Obando y Espinoza, previa solicitud de aprobación al obispo fray Tomás Manso para venir a trabajar a Cartago. ${ }^{32} \mathrm{~A}$ partir de 1657 se convirtió en vicario en Cartago hasta 1667. Se le conoce como licenciado, pero no se sabe el lugar en donde obtuvo su título. En el caso de su hermano Francisco de Echavarría 29 Iván Molina,Educación y sociedad en Costa Rica: de 1821 al presente (una historia de la educación no autorizada) Diálogos. Revista Electrónica de Historia. Vol 8 No 2Agosto 2007-Febrero 2008.Informe especial. http:/historia.fcs.ucr.ac.diálogos.htm consulta 10 de mayo.

30 Víctor Manuel Sanabria. Reseña Histórica de la Iglesia en Costa Rica, desde 1502 hasta 1850. (San José, DEI. 1984), 133.

31 Zúñiga, Edgar. Historia Eclesiástica de Nicaragua. Managua, Editorial Hispaner, 1996. pp. 98-100.

32 Archivo Nacional de Costa Rica, en adelante ANCR, Protocolos coloniales de Cartago, Exp 812, Octubre, 1657, f 9. Permuta entre Domingo de Echavarría y Diego de Obando. 
Navarro, no se le identifica como licenciado y tampoco hay alguna indicación de que tuviera algún título.

Otro sacerdote del que tenemos conocimiento que fue a prepararse a Nicaragua es Diego Angulo Gascón, criollo, quien sirvió muchos años a la iglesia de Granada y luego pasó a Cartago, ${ }^{33}$ lugar en que se desempeñó como vicario desde 1699 a $1717 .{ }^{34} \mathrm{El}$ estudio de estos tres casos nos indica que con un título o no, el hecho de estudiar en Nicaragua les brindó la oportunidad de ocupar en Cartago el puesto más importante de la Iglesia en Cartago, ser vicario, o sea el representante del obispo en Costa Rica.

Una vez establecido el Seminario San Ramón Nonato en León en 1680, nos encontramos que como uno de sus primeros alumnos fue Bernardo de Castellón, procedente de Nueva Segovia, se ordenó como cura y lo encontramos trabajando en 1705 en el norte de Nicaragua en el pueblo de Sitelpaneca. ${ }^{35}$ Entre los alumnos se encontraba también Manuel de Gavarrte, a él no le pudimos dar seguimiento pero su hermano el licenciado Salvador de Gavarrete es recomendado por el obispo Diego de Morcillo, como sujeto de conocida virtud y ejemplo. Además, señaló el obispo que realizó estudios en Guatemala, pero no se dice en cuál institución. ${ }^{36} \mathrm{En}$ el mismo documento emanado por el obispo Morcillo, se señaló también a Fernando de Carrión, colegial fundador del colegio San Ramón Nonato, que ejerció el oficio de teniente y en 1704 fue cura de Subtiaba. ${ }^{37}$ De igual manera se menciona a Nicolás Ramiro Zapata, también como colegial fundador, y que en el momento que se expide el documento es cura de Subtiaba. Esta información obtenida señala muy bien que tres de los siete alumnos que ingresaron al seminario continuaron siendo sacerdotes y pareciera que cursaron los cursos del seminario, como lo demuestra la recomendación del obispo en 1704 .

Conforme avanza el siglo XVIII, la información que encontramos es mejor, pero en la mayoría de los casos muy esporádica y se concentra a fines del siglo. Para Carlos Molina Argüello luego de la muerte del deán Pedro José Chamorro en agosto del 1781, no quedaba en el cabildo eclesiástico ni un solo miembro con título de doctor ni de bachiller siquiera. "Del clero 33 AGI, Guatemala, 362. León, abril, 1704. Carta del obispo Diego de Morcillo al Rey, recomendando diversos sujetos de su obispado cualquier nivel

34 Velázquez, El Sentimiento religioso y sus prácticas en la Diócesis de Nicaragua y Costa Rica. Siglos XVII y XVIII, 118.

35 Zúñiga, 184

36 AGI, Guatemala, 3622 de abril 1704 Carta del obispo Diego de Morcillo al Rey recomendando diversos sujetos de su obispado.

$37 \quad$ Ibid 
catedralicio, todos , menos Ayestes, que parece no los siguió, habían alcanzado apenas los estudios de Gramática y Moral, que era lo más corriente a la sazón en el clero.”38 En cuanto al clero vamos a tener sorpresas como el caso del doctor Juan de Santa Rosa Ramírez, que se graduó como doctor en Sagrados Cánones en la Universidad de San Carlos en 1771, cuando fueron expulsados los jesuitas de Guatemala fue nombrado vicerrector del Colegio San Francisco de Borja. Se destacó en Guatemala y llegó a tener la cátedra de Sagrados Cánones por la jubilación de Juan González Batres. Luego fue trasladado a Nicaragua, previo paso por la catedral de Comayagua en Honduras, a ocupar el puesto de maestrescuela en la Catedral de León. ${ }^{39} \mathrm{Al}$ llegar al cabildo le costó mucho que sus compañeros lo aceptaran dado que su preparación era muy superior a la de ellos, lo que trajo que se movieran las redes de los Vílchez y Cabrera ${ }^{40}$ en España para que así él no pudiera ocupar el puesto que le correspondía.

Por lo que señalado anteriormente y por el informe a la Corona de don Juan de Ayssa, ${ }^{41}$ la preparación formal obtenida por algunos miembros del clero, no tuvo la trascendencia que se podía esperar. De los 75 sacerdotes analizados por Ayssa, en 1787 encontramos que solo el 9.3\% tenía un título de formación superior. De ellos seis obtenidos en Guatemala y uno en España. Solo uno estaban en la sede de la Diócesis, es decir León, Juan de la Rosa Ramírez. Los otros no fueron tomados en cuenta para puestos importantes de la Diócesis. Pedro Ximena, cura de Granada, quien era noble, fue examinador sinodal, Bernardo Antonio Barraza y Juan Francisco de Bargas, Alejandro Secada fueron curas sueltos de Granada, es decir no tenían ni siquiera parroquia fija, a José Eusebio Yglesias, lo mandaron al pueblo de indios de Sitelpaneca y a Miguel Chamorro lo enviaron a la Villa de Nicaragua compuesta por ladinos e indios. ${ }^{42}$ Estos nombramientos de lugares alejados del centro y de poca importancia a nivel de la organización de la Diócesis muestran o que la educación formal no era importante o que los sacerdotes de León que no tenían buena preparación, o preferían tener lejos a sus posibles rivales.

El mismo Juan Ayssa, que hizo el informe, planteó la queja de la falta de interés de que los miembros del clero hijos de los nobles, no se preocupan por estudiar, lo que si hacían los $38 \quad$ Carlos Molina Argüello, Memorial de mi vida. Fray Blas Hurtado y Plaza. (Managua, Banco de América, 1977), lix.

$39 \quad$ Ibid., lxiii.

40 Carmela Velázquez, Las funciones y las relaciones sociales, económicas y políticas de los miembros del cabildo catedralicio de la Diócesis de Nicaragua y Costa Rica (1531-1850). En prensa en Revista de Historia de la Universidad de Costa Rica, del CIHAC, Universidad de Heredia.

41 AGI., Guatemala, 914, Informe del estado del clero en la Provincia de Nicaragua, 17 de octubre de 1787. $42 \quad$ Ibid. 
mestizos que veían en el sacerdocio un posible escalón de ascenso social. También Ayssa analiza lo que nos había llamado la atención, que los sacerdotes con una educación superior no eran los que estaban ubicados en los mejores lugares de la Diócesis, sino que parece que los mandaban lejos, en lugar de aprovechar sus conocimientos y su experiencia.

Encontramos que existía durante el siglo XVIII un cambio muy grande con respecto a la concepción de los sacerdotes con educación formal. En 1704, el obispo Diego de Morcillo recomienda a los alumnos del Seminario como "Como los sujetos más dignos que hay en el clero de este obispado, con sus méritos para que puedan ser ocupados cada uno en el empleo que V.M. hubiere por conveniente.” ${ }^{43}$ Esta recomendación de los graduados de seminario muestra que el obispo apreciaba su formación. Caso muy diferente en los años ochenta del mismo siglo, en que los sacerdotes preparados no estaban en los puestos importantes sino más bien son mandados a los pueblos alejados y en algunos casos no se les da ni una parroquia. Esto es algo que se debe de trabajar más y me propongo tratar de dilucidarlo. No podemos caer en generalizaciones de que era por malos comportamientos, porque es muy difícil que todos hubieran caído en problemas.

\section{Las capellanías}

Las capellanías representaron una práctica bastante común en la Diócesis de Nicaragua y Costa Rica. Las instituyeron hombres, mujeres, casados, casadas, viudos, viudas, solteros, solteras y sacerdotes. Fueron fundadas, las capellanías, por los mismos fundadores o por sus albaceas por medio de una escritura delante del Juzgado Real. Muchos testadores instituyeron capellanías en sus testamentos para tratar de que alguno de sus descendientes se hiciera sacerdote, a cambio el beneficiario debía retribuir la ayuda con la celebración de misas por la salvación de su alma. Los bienes sobre los que se instituía la renta podían ser ganado, bienes inmuebles y riquezas en general. Esta renta era de un 5\% sobre los bienes. En otros casos, se estipulaba la cantidad de dinero que debía otorgase al beneficiario en total o se le asignaba una cantidad por misa. ${ }^{44}$

Las capellanías tuvieron varios fines; en primer lugar una ayuda para la salvación del alma ya que por medio de su institución se pensaba que una vez muerto el fundador recibiría el beneficio que otorgaba a su alma la celebración de misas para las que había dejado una suma estipulada en la fundación de la capellanía. Por otro lado se convertían en la principal ayuda económica para el estudio de los parientes que quisieran convertirse en sacerdotes sin la cual no se le permitía el ingreso a los centros de estudio como lo fue el caso de los seminarios

43 AGI, Guatemala, 3622 de abril 1704 Carta del obispo Diego de Morcillo al Rey recomendando diversos sujetos de su obispado

44 Velázquez. Actitudes ante la muerte en el Cartago del siglo XVII,172-173. 
tridentinos. Además fueron una fuente de crédito muy importante para los miembros de la sociedad de la diócesis. ${ }^{45}$

Así, las capellanías se convirtieron en el mecanismo por excelencia para costear la educación y el mantenimiento de los hijos y otros parientes allegados, siempre que fueran varones, que estudiaran la carrera eclesiástica. Con el fin de disfrutar de la capellanía por el mayor tiempo posible, se impuso la costumbre de nombrar capellanes a niños pequeños, lo que permitía la Iglesia porque estaba interesada en fomentar la reproducción de eclesiásticos. ${ }^{46}$ Los niños o los jóvenes recibían el nombramiento de capellanes titulares y podían disfrutar del superávit que producía la capellanía hasta el momento de ordenarse o tomaban otro estado. Para cumplir con la obligación de las misas se nombraba un capellán interino o se mandaban a decir por algún sacerdote. Se pidió que hicieran recibos los que las celebraban para poder hacer constar que estas se realizaran. ${ }^{47}$

En el caso de que los niños o los jóvenes que habían sido instituidos como capellanes cuando se ordenaban de sacerdotes, se les instituía oficialmente como capellanes y, "a partir de ese momento, asumían personalmente la obligación de decir las misas y obtenían el total de la renta." ${ }^{48}$ Los jóvenes que tenían en una capellanía el título de capellanes y no mostraban interés en la carrera eclesiástica, al cumplir 30 años debían de renunciar a la capellanía. Por todo lo anterior podemos concluir que estas fundaciones se convirtieron en una ayuda muy importante para niños y jóvenes que quisieran estudiar y alcanzar una carrera eclesiástica o alguna otra de su preferencia.Aunque durante su periodo de estudios no podían disfrutar de su renta completa, 45 Dentro de la capellanía el principal se llamaba a la suma total de la plata o cacao que se hacía pesar sobre una hacienda, un hato o una casa, en la misma escritura se designaba cuál debía de ser el rédito, su distribución y si podía redimirse o no. Se nombraba patrón a quien correspondía la presentación y capellanes que generalmente eran los parientes de los fundadores que recibían el beneficio de los ramos. Inquilino, era la persona que tomaba en arrendamiento los bienes que respaldaban el principal, estaba obligado a entregar los réditos en una fecha señalada, a mantener en buen estado los bienes y procurar las mejoras necesarias. Si el principal era redimible, podía solicitar la redención al Juzgado Eclesiástico y otorgar la escritura, si no lo que le quedaba era la oblar, es decir renunciar el inquilinato para que otra persona lo tomara. Para que esto fuera legal debió de ser avalado por el Vicario, el Juez eclesiástico y el Síndico General en el caso de los conventos. Una vez aceptada se debía e hacer de nuevo escritura ante el juez competente. Cuando el inquilino había muerto o habían decrecido los bienes, el inquilinato se concedía por medio de remate al mejor postor. Este se celebró a la salida de la misa mayor. Previamente se había informado al Juez de capellanías de León el que mandaba fijar un edicto con toda la información de la capellanía para que las personas hicieran la postura con conocimiento de la capellanía a rematar. Se conoce como ramos de capellanía, que era una cantidad determinada de cuyos réditos se debían de emplear en misas por el difunto o para los estudios del sacerdote designado. Tomado de Sanabria Víctor Manuel. Datos Cronológicos para la Historia Eclesiástica de Costa Rica.(1774-1821). Recp. Vernor Rojas y Miguel Picado. San José, Ediciones CECOR.,1992. 16.

46 Gisela, Von Wobeser, Las capellanías de misas: su función religiosa, social y económica de la Nueva España. En: Cofradías, Capellanías y Obras Pías en la América Colonial. (México, Universidad Nacional Autónoma de México, 1998. 126.

$47 \quad$ Ibid. 127.

48 Ibid. 
porque debían de pagar a un sacerdote para que celebrara las misas, el superávit les permitía una renta importante para mantenerse. Además se debe de tomar en cuenta que si se creaban cuando el capellán era niño esto les daba la oportunidad de un ingreso hasta los 30 años y por consiguiente una ayuda muy importante para las familias para poder educar a sus hijos.

De esta manera las capellanías se convirtieron en un aspecto muy importante para nuestro trabajo sobre la educación formal del clero. Ellas permitieron que los futuros sacerdotes se pudieran preparar y además de acuerdo a las disposiciones del Concilio de Trento se convirtieron en necesarias para el ingreso al centro de estudio de la Diócesis de Nicaragua y Costa Rica, el Seminario San Ramón Nonato. En el caso de que el futuro sacerdote no tuviera acceso a una, otro sacerdote le cedía ese beneficio como lo hizo el doctrinero de Barba, fray Bernardo de Asiáin, que le cedió una capellanía de 368 pesos a Lorenzo Quesada. Este se ordenó y posteriormente fue cura de Heredia por muchos años. ${ }^{49}$

Ante la gran importancia que tenían las capellanías en su papel de ayuda a la salvación del alma, no solo los laico, las instituyeron, sino que también muchos sacerdotes que gozaron de una capellanía para su formación, también las crearon luego de haber sido formados o en su testamento, o se convirtieron en patronos para que se siguieran administrando los bienes de estas y así se pudieran seguir ordenando sacerdotes con sus rentas y también celebrando las misas por quienes las establecieron.

Para tratar de mostrar la importancia de las capellanías en la formación del clero de nuestra diócesis analizaremos algunas de ellas, dándoles seguimiento a través del tiempo para tratar de probar nuestra propuesta. En primer lugar, analizaremos las capellanías instauradas por el sacerdote Baltazar de Grado, primer sacerdote nacido en Costa Rica fue comisario del Santo Oficio de la Inquisición en Cartago, vicario provincial y juez eclesiástico. ${ }^{50}$ Su padre fue el capitán Juan Solano, y su madre doña Mayor de Benavídez en $1580 .{ }^{51}$

De sus padres, el presbítero Baltasar de Grado heredó una cuantiosa fortuna, que no solo incluía bienes en Costa Rica como la casa que tenía en Cartago sino también algunos bienes en Panamá. Instituyó tres capellanías, la primera el 3 de noviembre de 1627 por 500 pesos. Fue confirmada en León, Nicaragua, por el obispo Fray Fernando Núñez. ${ }^{52}$ La impuso sobre un

49 Thiel, 95.

$50 \quad$ AHA, Caja Número 3, folios 115-130. 3 de noviembre 1627.

51 Ibíd. p.96 y Marvin, Vega . "Las capellanías en Costa Rica: siglos XVII y XVIII” En: Revista Asogefi.

Año 1, Número 2 Julio-diciembre, 1996. Cuadro Genealógico N. ${ }^{\circ}$. La familia Solano Benavides, 176.

52 AHA,. Caja Número 3, folios 115-130. 3 de noviembre 1627. 
molino de moler trigo con un ingenio de agua en el campo de la ciudad de Cartago. ${ }^{53}$

La obligación que tenía el capellán, era decir dos misas, el primero y tercer domingo del mes al alba antes de amanecer para dar posibilidad a los pobres de oir la santa misa; pues en la ciudad de Cartago "hay mucha gente que por la necesidad de la tierra no tienen mantas las mujeres y los hombres faltan del vestido suficiente para poder ir de día a la iglesia." ${ }^{54}$ Las misas se debían rezar por su alma, la de sus padres y las de las almas a su encargo. Nombró como patrón a su tío, Juan Solano, que fue teniente gobernador en 1634 y tenía el grado de sargento mayor, además, fue encomendero de Quepo y Güisirí. Alcalde ordinario de Cartago en 1650 y murió en $1654 .{ }^{55}$ En 1628, fundó el presbítero de Grado otra capellanía en la que expresaba: "Patrón a Juan Solano su hermano. Por su muerte al pariente más cercano que hubiere en esta ciudad, si no existiere el capellán se nombren a los parientes cercanos asentados en Cartago, clérigos y presbíteros y piadosos y no habiendo nombren a curas de la ciudad." 56

El 23 de abril de 1636, el presbítero de Grado decidió fundar una nueva capellanía con un capital de 4030 pesos, en nueve escrituras hipotecarias hechas entre 1629 y 1630. La localizó en la iglesia parroquial de Cartago con la obligación de decir 177 misas anuales y pagar 20 pesos a la fábrica de la parroquia. Nombró como capellán al clérigo Domingo de Echavarría, quien sería su sucesor en el vicariato. La capellanía fue aceptada por el obispo Briceño en León y la erigió canónicamente. ${ }^{57}$

En 1648, en el mismo expediente de la capellanía, aparece que Juan Solano, señala como patrono el cambio de capellán, pues el nombrado por de Grado había muerto e instituyó siguiendo las instrucciones de su hermano, al pariente más cercano, el presbítero Alonso de Sandoval, sacristán mayor de la iglesia parroquial, lugar en que se debían decir las misas establecidas en la capellanía. Sandoval era sobrino del fundador de la capellanía y del patrón de ella. Con el pasar del tiempo, hay documentos que señalan al presbítero Domingo de Echavarría como representante de la misma capellanía, o sea, que llegó a ser el patrón. Este sacerdote, era hijo de Juan de Echavarría Navarro y de María de Sandoval, sobrina de Baltasar de Grado.

Don Juan de Echavarría Navarro era natural de los reinos de España, nacido en 1581 y en

$53 \quad$ Ibíd.

54 Thiel, 29.

55 Rafael, Obregón, Los gobernantes de la colonia, (San José, Editorial de la Universidad de Costa Rica, 1979),70-80.

$56 \quad$ AHA, Caja Número 3, fos. 115-130. 3 de noviembre 1627.

57 Thiel, 30. 
1618, fue nombrado en Madrid como tesorero de Costa Rica con 800 ducados al año. Se dice que enseguida de su llegada a Cartago, contrajo matrimonio con María de Sandoval, quien nació en 1589 y era hija de Francisco de Ocampo Golfín y de Inés de Benavidez. Don Juan de Echavarría fue tesorero de Costa Rica hasta 1632 cuando falleció. ${ }^{58}$

El presbítero Domingo de Echavarría Navarro fue patrón y capellán de la capellanía; era también mayordomo de la iglesia parroquial, comisario delegado de la Santa Cruzada, vicario y juez eclesiástico desde 1664 a 1673 y fue mayordomo de la cofradía de las Benditas Ánimas del Purgatorio. ${ }^{59}$ Como su antecesor, estudió en Nicaragua y fue cura de León hasta que en 1657 convino en trocar los beneficios con don Diego de Obando y Espinoza, cura de Cartago y ambos pidieron la aprobación del obispo don Fray Tomás de Manso, recién electo, y de esa manera, pudo regresar a su tierra natal, Cartago. ${ }^{60}$

Francisco y ${ }^{61}$ Domingo de Echavarría ${ }^{62}$ instituyeron como capellán a su sobrino, el presbítero Francisco de Salazar, sacristán mayor, quien era hijo de Fernando de Salazar y Ambrosía de Echavarría, sobrina de Domingo y Francisco de Echavarría Navarro. El padre del presbítero Salazar fue capitán de oficiales reales en 1646 y había sido regidor de la ciudad de León de Nicaragua. Además, fue tesorero de la Real Hacienda de 1666 a 1673 y regidor de la ciudad de Cartago durante muchos años y también fue el alcalde ordinario más antiguo por mucho tiempo y ostentó el título de regidor perpetuo de la ciudad. ${ }^{63}$ En su testamento dijo ser encomendero de los pueblos de Ujarrás, Barba y Garavito.

Fernando de Salazar instituyó una capellanía, pero no señaló como su capellán a su hijo Francisco, lo que sí hizo su hermana, Juana de Salazar, en 1694 que lo nombró como capellán interino mientras su hijo de 14 años se ordenaba. ${ }^{64}$ También su tío, Sebastián de Sandoval, como patrono de la capellanía fundada por su abuelo el capitán Francisco de Ocampo Golfín y, en virtud de lo dispuesto por el fundador, lo nombró como capellán. ${ }^{65}$ Sobre todo para que Francisco,

58 Manuel de Jesús Jiménez. Doña Ana de Cortabarría y otras noticias de antaño. San José, Editorial Costa Rica, 1981. p.126.

59 Claudia, Quirós La Era de la Encomienda. Colección Historia de Costa Rica.( San José, Editorial de la Universidad de Costa Rica. 1990), 87.

$60 \quad$ ANCR, Prot. de Cartago, Exp. 813, (1657), f.9.

61 ANCR, Prot. de Cartago, Exp. 836, (1687), f.49.

62 ANCR, Prot. de Cartago, Exp. 838, (1689), f.22v.

63 Obregón, 90-91.

64 ANCR, Prot. de Cartago, Exp. 844, (1694), fo. 43.

65 ANCR, Prot. de Cartago, Exp. 832, (1684), fo .20. 
como clérigo de menores, con el título de la capellanía se pudiera ordenar de sacerdote. En otros documentos se muestra que varias personas confiaron al presbítero Francisco, el puesto de capellán para que les celebrara las misas por sus almas y las de sus parientes en busca de la salvación. Entre esas personas, además de sus tíos los licenciados Francisco y ${ }^{66}$ Domingo de Echavarría ${ }^{67}$ se pueden citar el capitán Francisco de Ocampo Golfín, que por línea materna era su tío bisabuelo, lo que demuestra que se seguía la costumbre de ir nombrando como sucesores de las capellanías a los familiares que se ordenaran como sacerdotes. También siguió el mismo proceso su tío político, Francisco Arley o Arleguí cuando lo nombró capellán interino de la capellanía de su mujer, Juana de Echavarría, ya fallecida, mientras el hijo de ambos se ordenaba sacerdote y si no era así, serían los sobrinos de ella. ${ }^{68}$ También fue capellán interino pudo establecer parentesco y albacea de don Pedro Durán de Cháves. ${ }^{69}$

El análisis de estos tres presbíteros permite establecer que pertenecían a una misma familia, cuyo origen fueron el capitán Juan Solano y doña Mayor de Benavides. Este capitán al haber llegado como uno de los conquistadores, pudo lograr una serie de ventajas y fortuna que sus descendientes heredaron. A nivel de iglesia obtuvieron puestos importantes como el de vicario de Cartago y la posibilidad de prepararse en León de Nicaragua; se encargaron de varias capellanías, lo que les aseguró un ingreso representativo, pues como lo señalan los fundadores, las misas se debían pagar a dos pesos, un buen precio para la época, ya que otros documentos señalan que solían pagarse a un peso.

Es pertinente señalar que las capellanías continuaban a pesar de los años, como fue el caso ya indicado del capitán Francisco de Ocampo Golfín; de la capellanía de Baltasar de Grado hay documentos de 1693que aún la mencionan, por ejemplo el caso del alférez Pedro de Torres que se obliga en nombre de Salvador de Torres y su mujer doña Cecilia de Coronado, a favor de dicha capellanía. ${ }^{70}$ Esta capellanía continuó en el tiempo y todavía en 1800, estaba vigente y por consiguiente se rezaban las misas por de Grado y servían para la educación de futuros sacerdotes. Si tomamos en cuenta que se establecieron en 1627, 1628 y 1636 nos muestra que las misas $66 \quad$ ANCR, Prot. de Cartago, Exp. 836, (1687), fo .49.

67 ANCR, Prot. de Cartago, Exp. 838, (1689), fo .22v.

68 ANCR, Prot. de Cartago, Exp. 843, (1693), fo .123.

69 ANCR, Prot. de Cartago, Exp. 851, (1698), fo. 168.

$70 \quad$ ANCR, Prot. de Cartago, Exp. 843, (1693), fo. 30.

Claudia, Quirós, Et Al, “ Los vascos en la provincia de Costa Rica. Análisis de su posición social, económica y mentalidades colectivas. Siglos XVII y XVIII”, Revista del Archivo Nacional, 2004, 2000. 15

ANCR, Prot. de Cartago, Exp. 825, (1678), fo. 80. 
por el alma de Grado se dieron por alrededor de 170 años y además que sirvieron por todo este espacio de tiempo para ayudar a la formación de sacerdotes de Costa Rica.

Otras capellanías que brindaron su apoyo a los futuros presbíteros fueron las establecidas Francisco de Enciso Hita, que nombró por capellán al estudiante Félix Estevan de Hocés Navarro, que se encontraba estudiando en León. Este estudiante fue más tarde el único canónigo de Costa Rica que estuvo en el Cabildo Catedralicio de la catedral de León. ${ }^{71}$ Otro ejemplo de que las capellanías cumplieron con su cometido de formar sacerdotes, fue la que estableció el sargento mayor, Blas González Coronel de 2.200 pesos que impuso sobre sus haciendas de Matina y Tuis. Nombró como capellán a su hijo Manuel González Coronel. Este se ordenó con la capellanía y fue más tarde cura de Cartago y juez eclesiástico. Hemos utilizado algunos ejemplos para mostrar que las capellanías lograron sus objetivos, por supuesto que fueron muchas más, pero no podemos señalarlas a todas.

\section{Los centros de estudios en Guatemala}

En el estudio de la educación formal de la Diócesis de Nicaragua y Costa Rica, la relación que esta tuvo con los principales centros de educación de Guatemala fue vital, sobre todo, que como ya explicamos anteriormente, el Seminario San Ramón no podía otorgar grados, era necesario que los alumnos que quisieran obtenerlos se fueran a Guatemala con ese fin.

El primer seminario de estudio del Reino de Guatemala se fundó el 24 de agosto de 1597, e inició sus labores el 12 de julio de 1598 en la ciudad de Guatemala, fue el Seminario Conciliar de Guatemala, de acuerdo con lo decretado por el Concilio Tridentino en su capítulo diez y ocho de la sesión veinte y tres en que se le encargó a los prelados que se hicieran instituciones en cada una de la Diócesis de Seminarios para instruir en las buenas letras y costumbres los niños de doce años arriba para que sirvieran en las catedrales. ${ }^{72}$ Este seminario estuvo bajo la protección de María, tal es así que el uniforme que debía de usar debía de ser de paño azul, como el hábito de Nuestra Señora de la Concepción. Su fundación se llevó a cabo durante el obispado del tercer obispo de Guatemala, fraile Gómez de Córdoba. En él se impartían las clases de Gramática, Retórica, Cánones, Sagradas Escrituras, Homilías y Cómputo Eclesiástico, así como canto de órgano. Sus profesores debían de ser sacerdotes, miembros de la cofradía de la Asunción de Nuestra Señora. ${ }^{73}$

$71 \quad$ Thiel, 155 .

72 . Estrada, 183.

73 Diccionario Histórico Biográfico de Guatemala. (Guatemala, Fundación para la Cultura y el desarrollo 
Este seminario a pesar de que algunos autores niegan su permanencia en el tiempo, Estrada Monroy señala que en los archivos eclesiásticos de Guatemala existen no solamente las listas completas de los alumnos que se inscribieron desde 1601 a 1970, y que de cada uno de ellos existe un expediente completo, en el que aparece desde su partida de bautismo hasta la recepción de las diversas órdenes sacerdotales. ${ }^{74}$

Por otro lado, ya existía un pequeño colegio fundado por el obispo Marroquín en 1556, para cubrir las más elementales necesidades de la instrucción. ${ }^{75}$ Marroquín no solo lo fundó sino que dispuso en su testamento la constitución de un fondo económico, con el pago anual (terrazgo) de los indígenas de las milpas de Jocotenango, San Felipe, San Antón y San Dionisio de los Pastores. Además tuvo donaciones de Sancho Barahona y su mujer por un monto de 24.472 pesos. ${ }^{76}$ Los dominicos encontraron que este colegio se podía convertir en Universidad y extendieron un poder a favor de los procuradores de Cortes, para que ellos gestionasen ante su majestad la apertura de esta universidad. Su solicitud estuvo basada en que era el único lugar en que se enseñaba Teología, Artes y Gramática. En 1620 el presidente de la audiencia, Antonio Peraza de Ayala y Rojas dio la aprobación para que se instituyera el Colegio con el nombre de Santo Tomás de Aquino y "se pedía y se suplicaba a su Majestad y a su Real Consejo de Indias, se sirviera aprobar y confirmar la erección y fundación del colegio y de hacerle la merced d que en él se fundara Universidad.” 77

El solicitante añadía, que en el caso de que no se concediera el que fuera universidad, por lo menos al igual que en España, se le permitiera otorgar grados. Posteriormente se dio una lucha bastante fuerte con los jesuitas que ellos querían la universidad, a lo que se llegó fue que los jesuitas lograron no solo continuar con su Colegio San Francisco de Borja, sino que en 1640 se les otorgó el derecho de otorgar grados de Bachilleres, Licenciados, Maestros y Doctores. Esto de acuerdo a la concesión por medio de la Bula de su santidad Urbano VIII, que les concedía ese privilegio en todas las Indias Occidentales. ${ }^{78}$

La lucha por la Universidad continuó y culminó con su establecimiento el 18 de junio

Asociación de Amigos del país, 2004), 838.

$74 \quad$ Estrada, 194

75 Ibid., 106

$76 \quad$ Diccionario 904

77 Ricardo, Castañedo, Historia de la Real y Pontificia Universidad de san Carlos de Guatemala.

(Guatemala, Tipografía Nacional, 1947), 43.

78 Castañeda, 55. 
de 1687 con el nombre de "Real Pontificia Universidad de San Carlos", por medio de la bula emitida por Inocencio XI. ${ }^{79}$ La Universidad impartía las cátedras de Teología escolástica, Teología Moral, Cánones, Leyes, Medicina y dos lenguas indígenas. ${ }^{80}$

Con el traslado de la ciudad a Nueva Guatemala de la Asunción en 1777, se siguieron desarrollando los mismos cursos que se establecieron en sus Estatutos y Constituciones, redactados por el Oidor don Francisco de Sarassa y Arce a fines del siglo XVII y que conducían a la obtención en orden sucesivo de los grados de bachiller, licenciado, maestro y doctor. Estos estudios fueron los de teología, filosofía, derecho civil y canónico, medicina y lenguas indígenas. ${ }^{81}$

En el siglo XVIII se dio la reforma de la Universidad planteada por el franciscano, costarricense, que fue llamado a la Universidad como director, Antonio Liendo y Goicoechea, pero como bien lo señala Francisco Enríquez el aporte de Liendo y Goicoechea formó parte del desarrollo de la Ilustración en Guatemala."En este lugar, como en otras partes de América, se dio una transformación general del pensamiento, que fue determinada por la corriente filosófica y científica de la época." ${ }^{\prime 2}$ Por lo que su aporte no se debe de analizar fuera del contexto de la introducción de la ciencia en la región, especialmente en Guatemala. En lo que no hay que dejar de lado el análisis de las influencias de una gran variedad de movimientos filosóficos nacidos principalmente en la Europa de la época. ${ }^{83}$

La reforma del plan de estudios propuesta por Liendo y Goicoechea, recomendó ampliar el número de cátedras que ya se impartían agregar; medicina, y sagradas escrituras, pedidas por el claustro. En el antiguo curso de artes que se enseñaba en una sola cátedra introducir las de lógica, metafísica y moral. Otra cátedra nueva fue la de matemáticas, que consideraba necesaria para la física y se podían incluir otras materias relacionadas como la geometría, óptica, mecánica, astronomía y esfera. Además, se activó la cátedra del idioma cakchiquel. Otra innovación muy importante fue la cátedra de física experimental, en la que se impulsaba el estudio de autores europeos y el uso práctico de instrumentos y aparatos como el termómetro, máquinas neumáticas

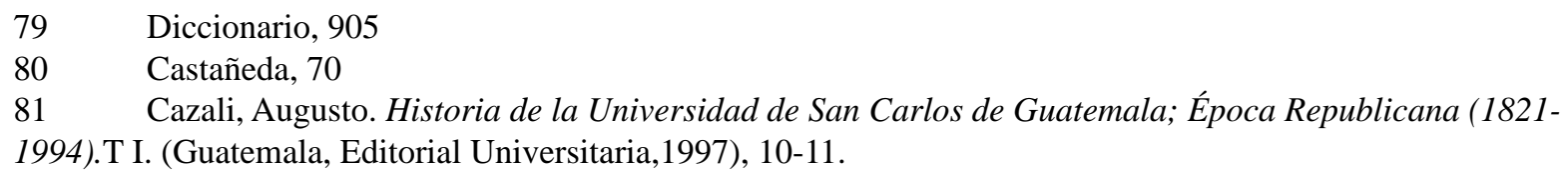
Centro América Diálogos Vol 6 N1 febrero agosto 2005, 252. http://historia.fcs.ucr.ac.cr/dialogos.htm acceso el 25 de abril.

83 Ibid. 
y eléctricas. En el curso de óptica se incluyeron la dióptrica y la catóptrica. ${ }^{84}$

Como ya mostramos, los centros de Guatemala tuvieron una gran importancia en la educación formal del clero en la Diócesis de Nicaragua y Costa Rica. Ya que a ellos recurrían para obtener los grados que no podía otorgar el San Ramón Nonato.

\section{A manera de conclusión}

La educación en la Diócesis de Nicaragua y Costa Rica se realizó en Nicaragua desde antes de que existiera el Colegio San Ramón Nonato y los que querían obtener grados debieron de trasladarse a Guatemala a alcanzarlos. Los obispos se preocuparon por la creación y mantenimiento del único centro de educación del clero en la Diócesis.

Las capellanías representaron una ayuda muy importante para que los sacerdotes estudiaran y en el caso de Costa Rica se mantuvieron vigentes por periodos de hasta más de cien años, para celebrar misas por sus fundadores y ayudando a estudiantes a convertirse en sacerdotes.

La percepción de un clero preparado sufrió cambios durante el siglo XVIII, en sus inicios se recomendaron los sacerdotes que habían estudiado en el Seminario San Ramón. Luego, los curas que tenían alguna preparación fueron mandados a curatos lejanos o pueblos de indios, pareciera que no se quería mantener cerca ni del cabildo que al parecer solo tenía un miembros con preparación o lejos aún del seminario, en lugar de aprovechar sus conocimientos y su experiencia.

Considero que este es un primer trabajo sobre la educación del clero, que quedan todavía muchas incógnitas por resolver, que serán en futuras investigaciones, como es el caso de las redes sociales que existieron dentro de los miembros del clero y de estos con las autoridades civiles y con las elites de la Diócesis.

$84 \quad$ Cazali, 11. 